\title{
SISTEM PENDUKUNG KEPUTUSAN KONSUMSI LISTRIK DENGAN IMPLEMENTASI IOT DAN FUZZY RULE MINING
}

\author{
Rival Biasrori ${ }^{1}$, I Wayan Agus Arimbawa², IGP Wirarama Wedashwara W. ${ }^{3}$ \\ 1,2,3Program Studi Teknik Informatika Universitas Mataram. \\ Jalan Majapahit nomor 62 Mataram 83125 \\ ${ }^{1}$ rival.biasrori@outlook.com, ${ }^{2}$ arimbawa@unram.ac.id, ${ }^{3}$ wirarama@unram.ac.id.
}

\begin{abstract}
Abstrat
Electrical energy is one of the needs of modern society which is very important and vital [1]. To measure power as a whole, resources for measuring equipment and people who control the use of energy are not cheap. For this reason, a relatively Internet of Things-based measurement system and artificial intelligence are needed. The system will be developed web-based with centralized processing and nodes for measuring power at load. To get data, sensors that can detect voltage and current are used, these sensors will send data through the internet by using IoT equipment to store data to the server. Data will be recorded using the PZEM-004T sensor and the results of the data will be mining using sequence mining to obtain a fuzzy membership degree in which the degree of membership is input to the results of the energy consumption decision support system later.
\end{abstract}

Key words: IoT, PZEM 004t Sensor, Sequence Mining, Fuzzy, Decision Support system.

\begin{abstract}
Abstrak
Energi listrik adalah salah satu kebutuhan masyarakat modern yang sangat penting dan vital [1]. Untuk mengukur daya secara keseluruhan, sumber daya untuk mengukur peralatan dan orang-orang yang mengendalikan penggunaan energi tidaklah murah. Untuk alasan ini, diperlukan sistem pengukuran berbasis Internet of Things dan kecerdasan buatan secara relatif. Sistem akan dikembangkan berbasis web dengan pemrosesan terpusat dan node untuk mengukur daya pada beban. Untuk mendapatkan data, sensor yang dapat mendeteksi tegangan dan arus digunakan, sensor ini akan mengirim data melalui internet dengan menggunakan peralatan IoT untuk menyimpan data ke server. Data akan direkam menggunakan sensor PZEM-004T dan hasil dari data tersebut akan ditambang menggunakan urutan penambangan untuk mendapatkan derajat keanggotaan fuzzy di mana tingkat keanggotaan dimasukkan ke hasil sistem pendukung keputusan konsumsi energi nanti.
\end{abstract}

Kata kunci: IoT, PZEM 004t Sensor, Sequence Mining, Fuzzy, sistem Pendukung Keputusan.

\section{PENDAHULUAN}

Energi listrik merupakan salah satu kebutuhan masyarakat modern yang sangat penting dan vital [1]. Peranan listrik sangat penting bagi setiap lapisan masyarakat bahkan listrik juga sangat dibutuhkan sebagai sarana produksi dan untuk kehidupan sehari- hari [2]. Seperti pada perguruan tinggi yang menggunakan listrik dalam beberapa kegiatan yaitu belajar mengajar, pengolahan data, kepegawaian, dan ujian sertifikasi secara online.

Hal tersebut dapat dicapai dengan melakukan perencanaan operasi yang baik dan tepat terkait pengadaan beban tambahan kedepannya [3]. Untuk melakukan pengukuran daya secara menyeluruh diperlukan sumberdaya peralatan ukur dan orang yang mengontrol penggunaan energi yang tidak murah. Untuk itu diperlukan sistem pengukuran relatif berbasis Internet of Things dan kecerdasan buatan. Internet of Things, atau dikenal juga dengan singkatan IoT, merupakan sebuah konsep yang bertujuan untuk memperluas manfaat dari konektivitas internet yang tersambung secara terus- menerus. Adapun kemampuan dari teknologi IoT adalah untuk berbagi data, remote control, dan mengontrol peralatan peralatan [4]

Sistem akan dikembangkan berbasis web dengan pemrosesan terpusat dan nodes untuk 
pengukuran daya pada beban. Untuk mendapatkan data, digunakan sensor yang dapat mendeteksi tegangan dan arus, sensor tersebut akan mengirimkan data melalui internet dengan memanfaatkan peralatan IoT untuk menyimpan data ke server.

Pemrosesan kecerdasan buatan yang digunakan dalam penelitian ini adalah fuzzy rule mining yang akan melakukan klasifikasi beban secara relatif atau kabur (fuzzy) berdasarkan pengenalan pola arus, tegangan dan durasi aktivitas beban [5]. Metode ini menggunakan rule extractor yang akan menghasilkan fuzzy rules atau selanjutnya disebut aturan fuzzy untuk setiap jenis beban. Bentuk rule extractor yang digunakan adalah jenis pohon yang diadaptasi dari genetik programming [6]. Hasil data yang dikirimkan sensor akan di-mining untuk menemukan pola penggunaan energi listrik untuk menentukan tingkat keborosannya. Kriteria tersebut digunakan untuk menentukan aturan aturan logika fuzzy sebagai bahan pengambilan keputusan. Output sistem pendukung keptusan ini nantinya dapat digunakan sebagai bahan pertimbangan untuk menentukan jenis peralatan yang menggunakan konsumsi listrik rendah daya agar penggunaan energi listrik digunakan secara efektif dan efisien.

\section{TINJAUAN PUSTAKA DAN DASAR TEORI}

\section{A. Tinjauan Pustaka}

Studi yang membuat perangkat prototype yang dapat memantau jumlah listrik. Namun, proses pengukuran diharuskan memotong atau memutus kawat pada panel yang berisiko timbulnya kerusakan baik pada prototype maupun sistem instalasi yang terpasang. Oleh karena itu, penelitian ini dikembangkan lebih lanjut dengan menggunakan sensor yang dapat melakukan pengukuran tanpa harus memotong daya dari panel distribusi sehingga tidak akan merusak peralatan. Sensor arus ACS sebagai sensor arus, Transformator step-down sebagai sensor tegangan, KWh meter sebagai sensor konsumsi energinya, dan ADC sebagai perubah nilai analog menjadi nilai digitalnya. Terdapat kelemahan pada penelitian ini dengan penggunaan sensor arus ACS yang diharuskan untuk memutus kawat fasa agar dapat terbaca nilai arusnya, hal ini berbahaya dari sisi keamaanan nya baik dari operator, peralatan listrik, protorype, maupun pada sistem. Tentu mengganggu jika harus melakukan pemutusan, kelemahan lain ialah pada BCM2835 yang belum memiliki fasilitas ADC, diperlukan ADC eksternal agar data sensor bisa diterima oleh BCM2835 tersebut namun BCM2835 telah memiliki fasilitas ethernet sebagai komunikasi datanya [7]. Adapun persamaan dengan penelitian sebelumnya adalah sama sama mengukur energi listrik namun pada penelitian yang akan dibuat menggunakan sensor tegangan dan arus serta menggunakan mikrokontroller berupa Wemos.

Pada studi ini menjelaskan bagaimana pemantauan online dari daya sistem dengan menggunakan sampel data yang direkam pada PMU ditempatkan di berbagai lokasi dengan frekuensi yang sama. Penelitian awal pada desain sistem pengukuran ini menggunakan BCM2835 Single board computer [8]. Adapun persamaan dengan penelitian sebelumnya adalah sama sama mengukur energi listrik namun pada penelitian yang akan dibuat menggunakan sensor tegangan dan arus serta menggunakan mikrokontroller berupa Wemos yang di mana data akan disimpan dalam server.

Untuk mendapatkan nilai konsumsi energi, hanya digunakan sensor arus, dan pemrosesan datanya menggunakan mikrokontroller BCM2835. Kemudian hasil pengukuran data akan disimpan dalam database MySQL dan dapat dilihat di website [9].

Adapun persamaan dengan penelitian sebelumnya adalah sama sama mengukur energi listrik namun pada penelitian yang akan dibuat menggunakan sensor tegangan dan arus serta menggunakan mikrokontroller berupa Wemos yang di mana data akan disimpan dalam server. Data yang ada pada server akan digunakan untuk proses pengambilan keputusan dengan fuzzy mining rule.

Adapun penelitian pendukung terkait konsumsi energi listrik dengan menggunakan sensor PZEM menggunakan Bahasa pemrograman python yang berjudul "Alat Monitoring Pemakaian Energi Listrik Berbasis Android Menggunakan Modul PZEM-004T" [10]. Pada penelitian ini hanya melakukan monitoring konsumsi energi listrik berbasis client server dan dapat dipantau menggunakan aplikasi mobile. 


\section{B. Dasar Teori}

B1. Internet of Things

Internet of Things (IoT) merupakan kumpulan benda-benda (things), berupa perangkat fisik (hardware/embedded sistem) yang mampu bertukar informasi antar sumber informasi, operator layanan ataupun perangkat lainnya yang terhubung kedalam sistem sehingga dapat memberikan kemanfaatan yang lebih besar.

B2. Arsitektur Internet of Things

Meski telah mulai diaplikasikan pada banyak bidang kehidupan sehari-hari, namun belum ada satu definisi yang baku dari IoT. Secara sederhana konsep IoT dapat digambarkan dengan bentuk arsitektur seperti ditunjukkan pada Gambar 2.2 [11].

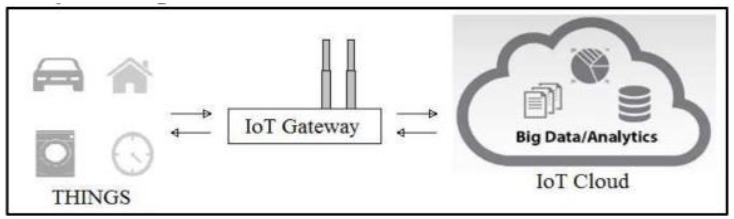

Gambar 2.1. Arsitektur Internet of Thungs

\section{B3. Mikrokontroller}

Mikrokontroller adalah sebuah sistem komputer yang seluruh atau sebagian besar elemennya dikemas dalam satu chip IC, sehingga sering disebut single chip microcomputer. Mikrokontroller merupakan sistem komputer yang mempunyai satu atau beberapa tugas yang sangat spesifik. Elemen mikrokontroller tersebut diantarnya adalah pemroses (processor), memori, input dan output [12].

\section{B4. Modul PZEM-004T}

Adalah sebuah modul sensor multifungsi yang berfungsi untuk mengukur daya, tegangan, arus dan energi yang terdapat pada sebuah aliran listrik. Modul ini sudah dilengkapi sensor tegangan dan sensor arus (CT) yang sudah terintegrasi. Dalam penggunaannya, alat ini khusus untuk penggunaan dalam ruangan (indoor) dan beban yang terpasang tidak diperbolehkan melebihi daya yang sudah ditetapkan.

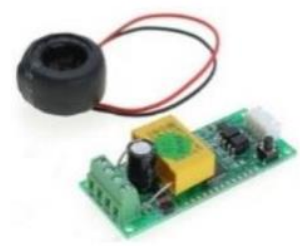

Gambar 2.2. Modul PZEM-004T

\section{B5. Fuzzy Mining Rule}

Metode kecerdasan buatan tanpa supervisor untuk melakukan data mining (klasifikasi atau klastering) berdasarkan rule extractor yang terdiri dari nodes fuzzy yang dirangkai dalam bentuk pohon atau jaringan yang akan di evaluasi berdasarkan relevansi setiap definisi nodes dan urutannya dalam rangkaian [5]. Metode ini diadopsi dari dua metode evolutionary computation yaitu genetic programming untuk bentuk pohon dan genetic network programming untuk bentuk jaringan yang mendefinisi kan rule extractor sebagai individu dalam sebuah populasi [6].

\section{B6. Wemos D1}

Wemos D1 merupakan platform elektronik open source yang berbasis pada Arduino dan chip ESP8266. Arduino pada dasarnya mengkombinasikan mikrokontroller keluarga Atmel dengan hardware standar ke dalam papan pengembangan dengan bootloader di dalamnya untuk pemrograman embedded secara plug and play [13].

\section{B7. Laravel}

Laravel adalah framework PHP yang menggunakan metode MVC (Model-ViewController) agar mempermudah dalam pembangunan sistem karena hanya fokus mengatur serta membuat model, view, dan controller aplikasi saja dimana dikembangkan pertama kali oleh Taylor Otwell [14].

\section{B8. Sistem Pendukung Keputusan}

Sistem Pendukung Keputusan adalah sistem pendukung berbasis komputer bagi para pengambil keputusan menajemen yang menangani masalahmasalah tidak [15]. Sistem Pendukung Keputusan (SPK) memadukan sumber daya intelektual dari individu dengan kapabilitas komputer yang meningkatkan kualitas keputusan [16].

\section{B9. Besaran Listrik}

Hal penting untuk diketahui dari beberapa besaran listrik diantaranya adalah arus, tegangan dan daya. Flowchart dari tahapan penelitian ini dapat dilihat pada Gambar 3 .

B10. Arus Listrik

Listrik ada di alam disebabkan adanya muatan listrik, pergerakan muatan menimbulkan arus listrik, coulomb adalah satuan yang menyatakan muatan, tujuan dari sebuah rangkaian listrik adalah memindahkan 
muatan sepanjang lintasan yang diinginkan. Definisi arus itu sendiri adalah laju perubahan muatan persatuan waktu yang diukur dalam satuan ampere (A). Arus listrik dapat dirumuskan dengan persamaan berikut [17]:

$$
I=\frac{d Q}{d t}
$$

Dimana :

I = Arus listrik dalam satuan ampere (A)

$\mathrm{Q}=$ Muatan listrik dalam satuan coulomb (C)

$\mathrm{t}=$ Waktu dalam satuan $\operatorname{detik}(\mathrm{s})$

B11. Tegangan

Tegangan listrik adalah besarnya beda energi potensial antara dua buah titik yang diukur dalam satuan volt (V). Tegangan dapat juga diartikan sebagai joule per coulomb. Tegangan didefinisikan sebagai kerja yang diperukan untuk memindahkan satu unit muatan dari satu terminal ke terminal yang lain [17]:

$$
\mathbf{V}=\frac{d W}{d Q}
$$

Dimana:

$\mathrm{V}=$ Tegangan dalam satuan volt $(\mathrm{V})$

$\mathrm{W}=$ Energi dalam satuan joule (J)

$\mathrm{Q}=$ Muatan dalam satuan coulomb (C)

\section{B12. Daya daan Faktor Daya}

Laju energi yang diserap ataupun yang dikirim disebut daya, sedangkan daya listrik adalah banyaknya energi listrik yang mengalir setiap detik atau joule per second yang diukur dalam satuan watt (W). Daya listrik dirumuskan dengan persamaan berikut [17]:

$$
\begin{aligned}
& \mathbf{W}=\mathbf{P} . \mathbf{t} \\
& \mathbf{P}=\frac{\mathrm{dW}}{d t}
\end{aligned}
$$

Dimana:

$\mathrm{P}=$ Daya dalam satuan watt $(\mathrm{W})$

$\mathrm{W}=$ Energi dalam satuan joule (J)

$\mathrm{t}=$ Waktu dalam satuan detik ( $\mathrm{s}$ )

Energi listrik didefinisikan sebagai laju penggunaan daya listrik dikalikan dengan selama waktu tersebut [18]. Satuan SI untuk energi listrik adalah Joule (J), namun dalam kehidupan sehari-hari lebih dikenal dengan kiloWatthour (kWh) [19]. Pada sebuah rangkaian listrik, hubungan antara arus dan tegangan dijelaskan dengan hukum ohm dimana arus berbanding lurus dengan tegangan dan berbanding terbalik dengan hambatan. Hambatan yang dimaksud adalah hambatan pada rangkaian yang dapat menghalangi aliran arus. Hambatan dinotasikan dengan $\mathrm{R}$ dan diukur dalam satuan ohm $(\Omega)$ [19].

Dimana :

$$
\begin{gathered}
\mathbf{I}=\frac{V}{R} \\
\mathbf{R}=\frac{V}{I} \\
\mathbf{V}=\mathbf{I} \mathbf{R}
\end{gathered}
$$

$\mathrm{I}=$ Arus dalam satuan ampere $(\mathrm{A})$

$\mathrm{V}=$ Tegangan dalam satuan volt $(\mathrm{V})$

$\mathrm{R}=$ Hambatan (resistance) dalam satuan ohm

$(\Omega)$

Selanjutnya hubungan arus, tegangan dan daya dijelaskan dengan persamaan berikut

$$
\begin{gathered}
\mathbf{P}=\frac{d W}{d t} \\
\mathbf{P}=\mathbf{I} \mathbf{V} \\
\mathbf{P}=\mathbf{I} 2 \mathrm{R} \\
\mathrm{V}=\frac{P}{I}
\end{gathered}
$$

Pada jaringan listrik AC dengan bentuk gelombang sinusoidal dikenal beberapa jenis bentuk daya, diantaranya adalah daya kompleks, daya aktif dan daya reaktif [17].

\section{METODOLOGI PENELITIAN}

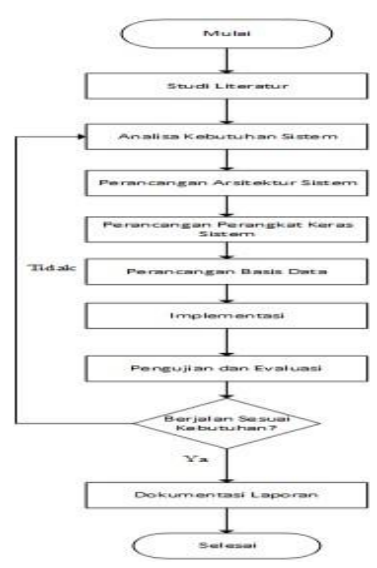

Gambar 3.1. Flowchart Tahap-tahap Penelitian

\section{A. Perancangan Arsitektur Sistem}

Pada tahap perancangan arsitektur sistem akan dibuat rangkaian perangkat keras yang akan digunakan untuk mengukur penggunaan energi pada penelitian ini. Gambar 4 merupakan gambaran arsitektur sistem untuk 
pengukuran energi listrik yang dimana pengukuran ini menggunakan sensor pzem yang merupakan sensor arus sekaligus dengan sensor tegangan.

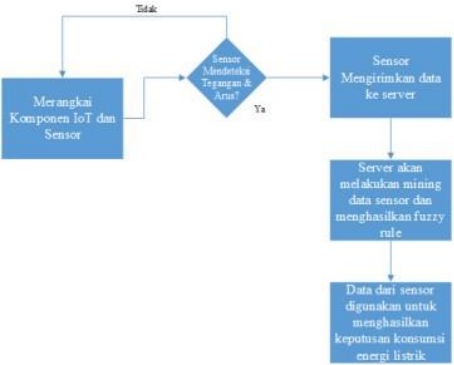

Gambar 3.2. Rancangan Arsitektur Sistem

\section{B. Perancangan perangkat keras sistem}

Perancangan perangkat keras sistem dapat dilihat pada Gambar 5. Dimana controller yang digunakan disini adalah wemos D1, dikarenakan untuk menghemat penggunaan kabel maka digunakan controller wemos yang memiliki dukungan konektivitas Wi-Fi. Untuk pemrosesan data yang didapat oleh sensor digunakan raspberry dengan sistem operasi Raspbian. Untuk memproses data sensor lebih lanjut maka digunakan sistem pendukung keputusan yang berbasis fuzzy untuk mendapatkan kesesuaian penggunaan dari konsumsi energi listrik tersebut.

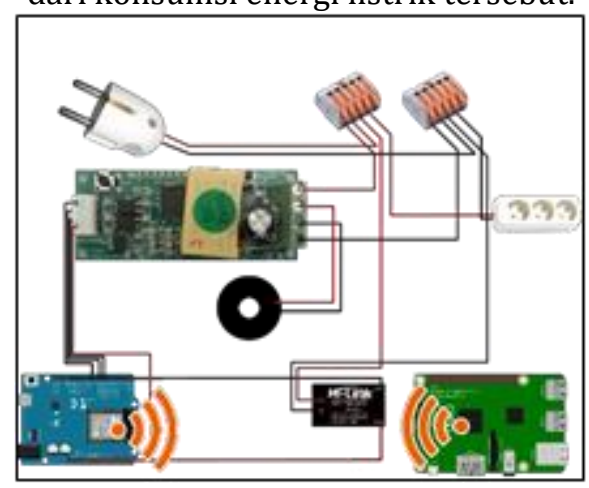

Gambar 3.3. Perancangan perangkat keras sistem

C. Perancangan Basis Data

Pada perancangan energi listrik berbasis IoT ini memiliki 5 entitas yaitu entitas seperti pada Gambar 3.5 .
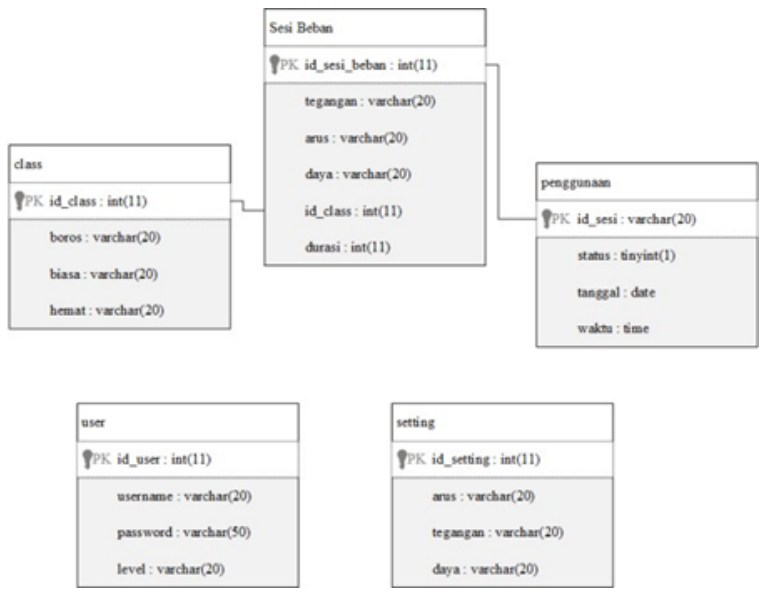

Gambar 3.4. Rancangan database pengukuran energi listrik berbasis IoT

\section{Rancangan Perangkat Lunak}

Pada sistem pengukuran energi listrik dengan berbasis IoT yang akan dibangun terdapat 2 buah aplikasi yang dibuat yaitu kontrol aplikasi yang digunakan untuk mengontrol perangkat keras dan sistem pendukung keputusan berbasis fuzzy yang digunakan untuk memproses penguunaan data konsumsi listrik yang kemudian akan disimpulkan tingkat kesesuaian penggunaannya.

\section{E. Rancangan Kontrol Aplikasi}

Control Application merupakan aplikasi yang akan dipasangkan pada arduino dan digunakan untuk mengendalikan sensor dan modul untuk dapat menerima input dan memberikan output.

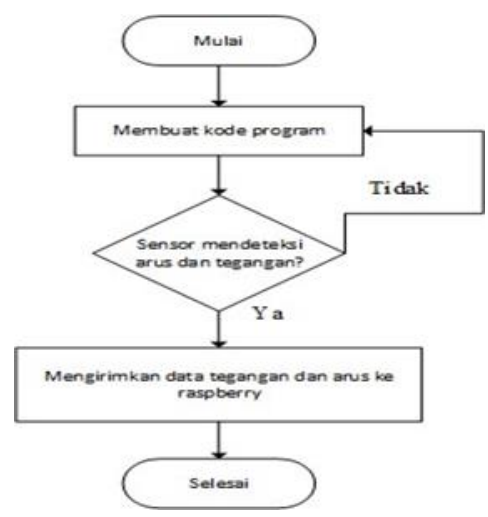

Gambar 3.5 Rancangan control aplikasi a. Gambaran usecase aplikasi pendukung keputusan konsumsi listrik dapat dilihat pada Gambar 3.6. 


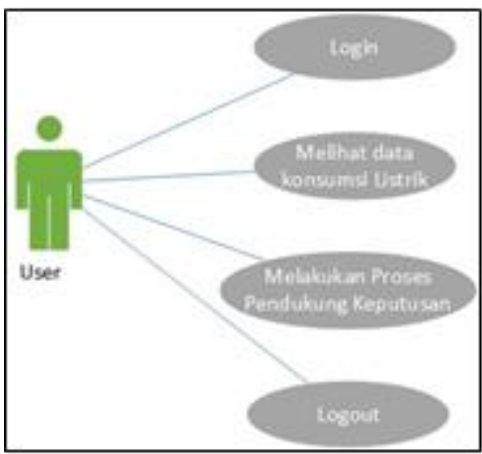

Gambar 3.6. Rancangan usecase aplikasi b. Prototype User Interface

\section{F. Rancangan Sistem Pendukung Keputusan}

Sistem Pengukuran konsumsi daya merupakan aplikasi berbasis web untuk melihat data penggunaan konsumsi energi lisrik yang dimana nantinya data tersebut akan di olah untuk menentukan tingkat kesesuaian penggunaan listrik seperti hemat, biasa dan boros. Pengembangan aplikasi web ini berbasis pada framework laravel dengan rancangan usecase dan user interface sebagai berikut:

Perancangan User interface Sistem Pendukung Keputusan konsumsi energi listrik ini merupakan bagian dari perancangan perancak lunak. Pada tahap ini akan dibuat user interface dari sistem pendukung keputusan berbasis website yang dimana dapat dilihat sebagai berikut:

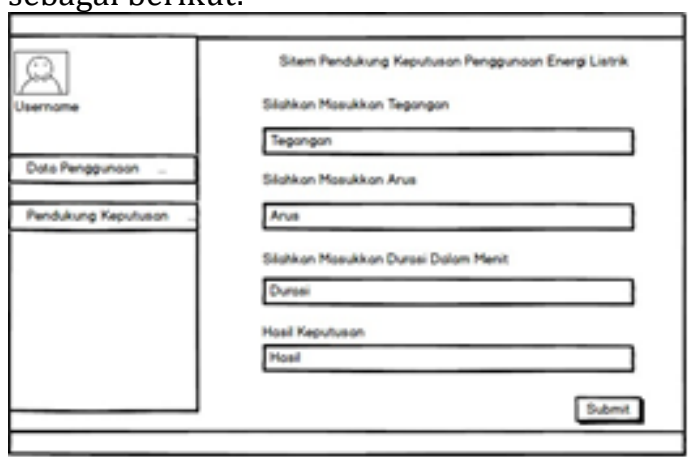

Gambar 3.7. Rancangan menu pendukung

keputusan

Gambar 8 merupakan tampilan menu pendukung keputusan untuk melihat hasil keputusan. Dimana dapat memasukkan data manual berupa jumlah tegangan, arus dan durasi penggunaan yang dimana akan menbampilkan hasil keputusan konsumsi energi listriknya.

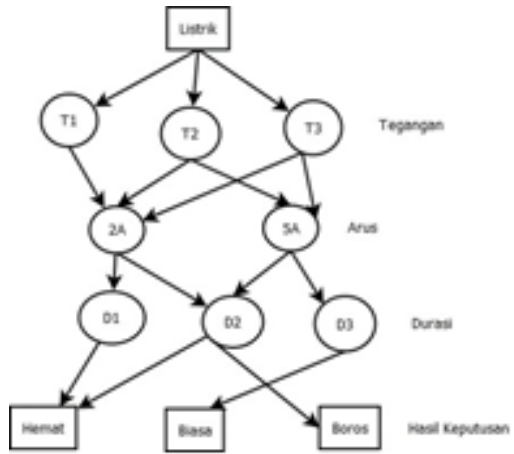

Gambar 3.8. Model pohon rule extractor

Penjelasan pada Gambar 9 adalah sebagai berikut: Parameter yang diukur pada usulan ini adalah tegangan arus dan durasi. Terdapat tiga jenis tegangan yaitu tinggi, normal dan rendah. Untuk durasi yaitu sebentar, biasa dan Lama. Untuk arus menggunakan nilai 2 Ampere sampai dengan 5 Ampere Hasil dari data tegangan, arus dan durasi tersebut akan menghasilkan keputusan konsumsi energi listrik berupa tiga keputusan yaitu hemat, biasa dan boros. Hasil keputusan ini merupakan hasil yang ditentukan oleh sistem itu sendiri berdasarkan dengan fuzzy mining rule, disini user hanya mengimplementasikan rumus yang sudah ada kedalam program dan selanjutnya sistem yang akan menentukan hasilnya. Contoh logika untuk perhitungan dan rule yang digunakan adalah sebagai berikut:

Laptop dengan output $19 \mathrm{v}$ dan arus 3.42 ampere digunakan dengan durasi 20 menit. Maka jumlah daya yang dihabiskan adalah sebagai berikut:

Jumlah daya = Daya (KWh) $x$ Durasi (Jam) Dimana, daya $=$ Tegangan $\mathrm{x}$ Arus. Sehingga daya yang digunakan oleh adaptor laptop tersebut adalah $19 *(3.42 / 1000) * 0.2=0.012 \mathrm{KWh}$ dalam sehari. Jika dikalikan dalam satu bulan maka penggunaan daya adaptor laptop sebesar 0.012 * $30=0.36 \mathrm{KWh}$. hasil fuzzy mining rule dari pohon pada gambar 3.8 .

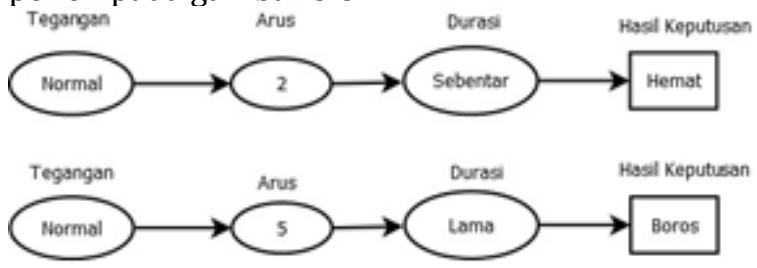

Gambar 3.9. Contoh hasil fuzzy mining rule 
G. Implementasi Sistem

1. Penyusunan Perangkat Wemos D1, sensor arus dan tegangan, stepdown, Wago, akan dihubungkan menggunakan kabel jumper dan kabel listrik.

2. Pembangunan Control Application ke dalam Wemos D1 dengan menggunakan bahasa pemrograman $\mathrm{C}++$.

3. Pembangunan Database menggunakan MySql. XAMPP akan digunakan sebagai alat bantu dalam proses implementasi Database ke dalam Raspberry Pi.

4. Pembangunan Sistem Pendukung Keputusan KonsumsiEnergi Listrik dibuat dalam bentuk Web Service yang akan diimplementasikan ke dalam Wemos D1 dengan menggunakan framework Laravel. Sublime Text digunakan sebagai alat bantu dalam proses implementasi Web Service ke dalam Wemos D1 dan pembangunan Sistem Pendukung Keputusan Konsumsi Energi.

\section{HASIL DAN PEMBAHASAN}

Data yang digunakan pada penelitian ini berupa data dari alat alat elektronik seperti computer, switch, access point, charger hp, charger laptop, dispenser dan printer. Adapun pengambilan data yang dilakukan sebanyak 7 hari kerja. Data penggunaan berdasarkan beban yang terhubung dapat dilihat pada tabel berikut:

Tabel I Tabel data berdasarkan hasil sensor

\begin{tabular}{|c|c|c|c|c|c|c|}
\hline Tanggal & $\begin{array}{l}\text { Max } \\
\text { tepangen }\end{array}$ & $\begin{array}{l}\text { Min } \\
\text { tegrangan }\end{array}$ & $\begin{array}{l}\text { Max } \\
\text { avus }\end{array}$ & Min arss & Max daya & Min daya \\
\hline $31 / 122018$ & $229.90 \mathrm{~V}$ & $225.10 \mathrm{~V}$ & $0.63 \mathrm{~A}$ & $0.05 \mathrm{~A}$ & $94.00 \mathrm{~W}$ & $5.00 \mathrm{~W}$ \\
\hline $0201 / 2019$ & $232.60 \mathrm{~V}$ & $225.40 \mathrm{~V}$ & $0.97 \mathrm{~A}$ & $0.07 \mathrm{~A}$ & $149.00 \mathrm{~W}$ & $8.00 \mathrm{~W}$ \\
\hline $0301 / 2019$ & $232.30 \mathrm{~V}$ & $228.60 \mathrm{~V}$ & $0.4 \mathrm{~A}$ & $0.2 \mathrm{~A}$ & $84.00 \mathrm{~W}$ & $48.00 \mathrm{~W}$ \\
\hline $0401 / 2019$ & $232.80 \mathrm{~V}$ & $224.20 \mathrm{~V}$ & $0.5 \mathrm{~A}$ & $0.1 \mathrm{~A}$ & $121.00 \mathrm{~W}$ & $9.00 \mathrm{~W}$ \\
\hline $05: 01 / 2019$ & $230.00 \mathrm{~V}$ & $224.50 \mathrm{~V}$ & $0.54 \mathrm{~A}$ & $0.09 \mathrm{~A}$ & $107,00 \mathrm{~W}$ & $9.00 \mathrm{~W}$ \\
\hline $0701 / 2019$ & $233.00 \mathrm{~V}$ & $223.00 \mathrm{~V}$ & $1.42 \mathrm{~A}$ & $0.09 \mathrm{~A}$ & $410.00 \mathrm{~W}$ & $9.00 \mathrm{~W}$ \\
\hline $0801 / 2019$ & $237,30 \mathrm{~V}$ & $227.20 \mathrm{~V}$ & $1.95 \mathrm{~A}$ & $011 \mathrm{~A}$ & $45200 \mathrm{~W}$ & $800 \mathrm{~W}$ \\
\hline
\end{tabular}

Realisasi penyusunan perangkat keras dari Sistem Pendukung Keputusan Konsumsi Energi Listrik dengan Implementasi IoT dan Fuzzy Rule Mining dapat di lihat pada gambar 4.1.

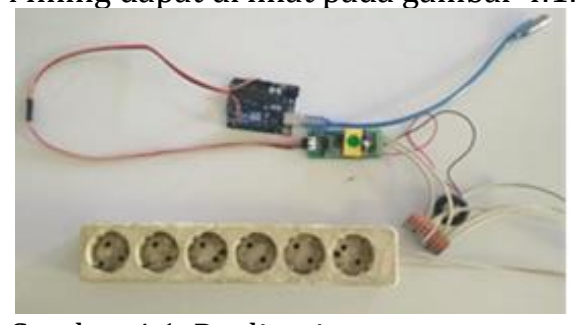

Gambar 4.1. Realisasi penyusunan perangkat keras system
Arduino Uno digunakan sebagai mikrokontroler. Wago digunakan sebagai terminal penghubung kabel listrik, Sensor PZEM-004T sebagai sensor utama yang diaman dapat langsung menampilkan hasil perekaman data energi listrik seperti tegangan, arus, dan daya yang digunakan beban.

Tabel II Hasil perhitungan data penggunaan hari pertama

\begin{tabular}{|c|c|c|}
\hline Data & Tegangan & Arus \\
\hline Average & 22.763 .952 .086 .308 & 0.10452800253847 \\
\hline Stddev & 5.182 .514 .005 .077 & 0.023303157226718 \\
\hline Min & 225.00 & 0.00 \\
\hline Max & 229.90 & 0.63 \\
\hline Median & 227.90 & 0.06 \\
\hline Submedian1 & 226.90 & 0.00 \\
\hline Submedian2 & 228.50 & 0.21 \\
\hline
\end{tabular}

\begin{tabular}{|c|c|c|}
\hline Data & Daya & Wh \\
\hline Average & 13.899 .016 .341 .425 & 0.0079327304458195 \\
\hline Stddev & 45.441 .369 .189 .275 & 0.0079327304458195 \\
\hline Min & 0.00 & 0 \\
\hline Max & 93.00 & 1 \\
\hline Median & 4.00 & 0 \\
\hline Submedian1 & 2.00 & 0 \\
\hline Submedian2 & 29.00 & 0 \\
\hline
\end{tabular}

Tabel III Hasil perhitungan data penggunaan hari kedua

\begin{tabular}{|c|c|c|}
\hline Data & Tegangan & Arus \\
\hline Average & 22.827 .351 .047 .166 & 0.38446423391544 \\
\hline Stddev & 52.114 .209 .106 .573 & 0.16796343331208 \\
\hline Min & 225.40 & 0.07 \\
\hline Max & 232.60 & 0.97 \\
\hline Midian & 227.80 & 0.35 \\
\hline submidian1 & 227.30 & 0.29 \\
\hline submidian2 & 228.70 & 0.51 \\
\hline
\end{tabular}

\begin{tabular}{|c|c|c|}
\hline Data & Daya & Wh \\
\hline Average & 68.796 .020 .189 .128 & 0.040146197134072 \\
\hline Stddev & 55.841 .300 .110 .228 & 0.069617682891454 \\
\hline Min & 8.00 & 0 \\
\hline Max & 147.00 & 23 \\
\hline Midian & 64.00 & 0 \\
\hline submidian1 & 52.00 & 0 \\
\hline submidian2 & 92.00 & 0 \\
\hline
\end{tabular}

Standar deviasi, nilai minimum dan maksimum dari masing-masing atribut berdasarkan hari dapat dilihat pada Table II dan 
Table III yang dicatat melalui sensor. Terjadi peningkatan penggunaan daya pada hari kedua penelitian, hal ini dikarenakan lebih banyaknya perangkat yang terhubung ke aliran listrik dibandingkan dengan hari sebelumnya, dimana rata-rata penggunaan daya pada hari pertama adalah 13.899 watt dan pada hari kedua adalah 68.796 watt yang berati gap penggunaan daya rata-rata diantara kedua hari tersebut adalah 54.987 watt.

Tabel IV Hasil perjitungan data penggunaan hari ketiga

\begin{tabular}{|c|c|c|}
\hline Data & Tegangan & Arus \\
\hline Average & 23.042 .868 .160 .117 & 0.31493940506793 \\
\hline Stddev & 53.104 .239 .403 .844 & 0.099622793487576 \\
\hline Min & 228.60 & 0.28 \\
\hline Max & 232.30 & 0.42 \\
\hline Midian & 230.50 & 0.31 \\
\hline submidian1 & 230.10 & 0.30 \\
\hline submidian2 & 230.90 & 0.32 \\
\hline
\end{tabular}

\begin{tabular}{|c|c|c|}
\hline Data & Daya & Wh \\
\hline Average & 5.879 .764 .965 .112 & 0.033051781123761 \\
\hline Stddev & 3.484 .646 .835 .598 & 0.033051781123761 \\
\hline Min & 48.00 & 0 \\
\hline Max & 84.00 & 1 \\
\hline Midian & 58.00 & 0 \\
\hline submidian1 & 55.00 & 0 \\
\hline submidian2 & 61.00 & 0 \\
\hline
\end{tabular}

Tabel V Hasil mining data penggunaan hari keempat

\begin{tabular}{|c|c|c|}
\hline Data & Tegangan & Arus \\
\hline Average & 22.838 .743 .923 .061 & 0.25834284506449 \\
\hline Stddev & 52.166 .026 .690 .444 & 0.071646110758821 \\
\hline Min & 224.20 & 0.10 \\
\hline Max & 232.80 & 0.58 \\
\hline Midian & 228.40 & 0.26 \\
\hline submidian1 & 227.60 & 0.22 \\
\hline submidian2 & 229.30 & 0.28 \\
\hline
\end{tabular}

\begin{tabular}{|c|c|c|}
\hline Data & Daya & Wh \\
\hline Average & 45.434 .844 .641 .725 & 0.02573451701543 \\
\hline Stddev & 23.379 .943 .458 .043 & 0.02573451701543 \\
\hline Min & 9.00 & 0 \\
\hline Max & 121.00 & 1 \\
\hline Midian & 46.00 & 0 \\
\hline submidian1 & 37.00 & 0 \\
\hline submidian2 & 52.00 & 0 \\
\hline
\end{tabular}

Tabel VI Hasil mining data penggunaan hari kelima

\begin{tabular}{|c|c|c|}
\hline Data & tegangan & Arus \\
\hline Average & 22.762 .113 .546 .936 & 0.24436137655361 \\
\hline Stddev & 51.815 .708 .790 .204 & 0.080303322715635 \\
\hline Min & 224.50 & 0.09 \\
\hline Max & 230.00 & 0.54 \\
\hline Midian & 227.90 & 0.26 \\
\hline submidian1 & 227.30 & 0.10 \\
\hline submidian2 & 228.40 & 0.38 \\
\hline
\end{tabular}

\begin{tabular}{|c|c|c|}
\hline Data & daya & Wh \\
\hline Average & 40.343 .451 .377 .178 & 0.022796827181313 \\
\hline Stddev & 24.814 .042 .220 .973 & 0.022796827181313 \\
\hline Min & 9.00 & 0 \\
\hline Max & 107.00 & 1 \\
\hline Midian & 48.00 & 0 \\
\hline submidian1 & 10.00 & 0 \\
\hline submidian2 & 68.00 & 0 \\
\hline
\end{tabular}

Tabel VII Hasil mining data penggunaan hari keenam

\begin{tabular}{|c|c|c|}
\hline data & tegangan & Arus \\
\hline average & 23.032 .619 .444 .088 & 0.49460676316126 \\
\hline stddev & 53.054 .793 .974 .638 & 0.27905146022799 \\
\hline min & 223.00 & 0.09 \\
\hline max & 233.00 & 1.42 \\
\hline midian & 230.40 & 0.47 \\
\hline submidian1 & 229.60 & 0.36 \\
\hline submidian2 & 231.10 & 0.63 \\
\hline
\end{tabular}

\begin{tabular}{|c|c|c|}
\hline data & daya & Wh \\
\hline average & 81.966 .504 .419 .111 & 0.045984372998591 \\
\hline stddev & 77.906 .946 .970 .667 & 0.045984372998591 \\
\hline min & 9.00 & 0 \\
\hline max & 335.00 & 1 \\
\hline midian & 76.00 & 0 \\
\hline submidian1 & 60.00 & 0 \\
\hline submidian2 & 106.00 & 0 \\
\hline \hline
\end{tabular}

Tabel VIII Gap penggunaan antara hari percobaan dalam satuan watt

\begin{tabular}{|c|c|c|c|c|c|c|}
\hline $\begin{array}{c}\text { Gap hari } \\
\text { ke }\end{array}$ & 1 & 2 & 3 & 4 & 5 & 6 \\
\hline 1 & 0 & 54.987 & 8.02 & 31.535 & 26.444 & 68.067 \\
\hline 2 & 54.987 & 0 & 62.917 & 23.362 & 28.453 & 13.17 \\
\hline 3 & 8.02 & 62.917 & 0 & 39.555 & 34.464 & 76.087 \\
\hline 4 & 31.535 & 23.362 & 39.555 & 0 & 5.091 & 36.532 \\
\hline 5 & 26.444 & 28.453 & 34.464 & 5.091 & 0 & 41.623 \\
\hline 6 & 68.067 & 13.17 & 76.087 & 36.532 & 41.623 & 0 \\
\hline
\end{tabular}

Total gap penggunaan daya dapat dilihat pada table VIII dimana telah dipaparkan jumlah penggunaan daya berdasarkan hari kerja, dimana data daya ini diambil data rata rata daya yang digunakan dalam satu hari kerja laboratorium mulai dari pukul 9.00 WITA sampai dengan pukul 18.00 WITA. 
Hasil daripada mining data tersebut juga akan menghasilkan data berupa sequence data untuk masing masing parameter seperti arus daya dan tegangan. Dimana data sequence hasil mining inilah yang merupakan input fuzzy untuk system pendukung keputusannya. Berikut merupakan salah satu data yang didapatkan dari sequence mining pada parameter arus

Berikut merupakan contoh hasil implementasi data yang diperoleh ke dalam system pendukung keputusan yang telah dibangun berbasiskan web.

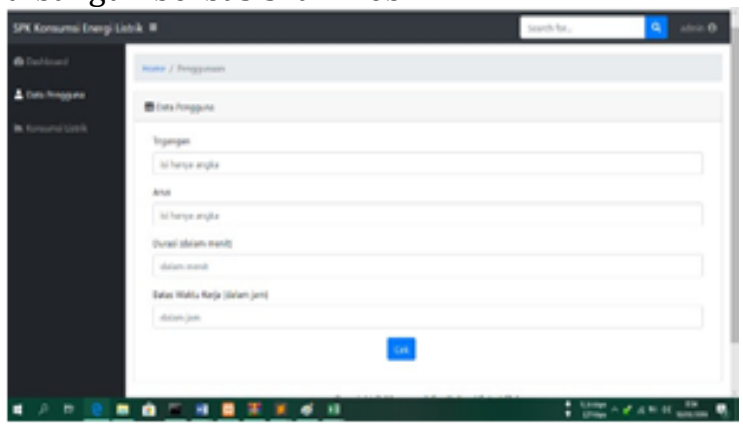

Gambar 12 Tampilan halaman awal system pendukung keputusan

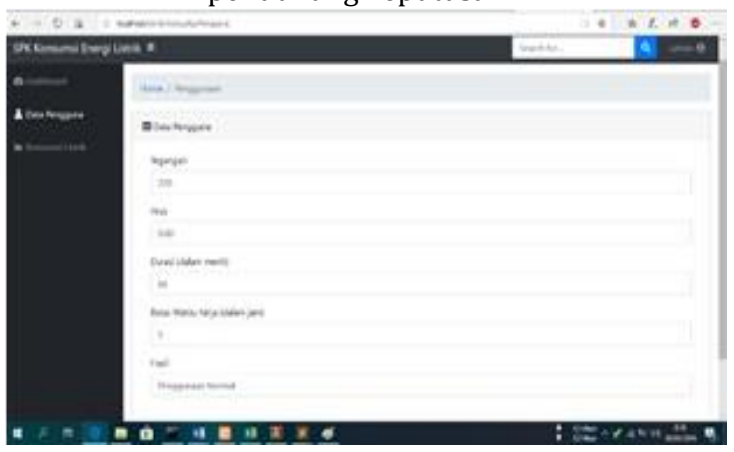

Gambar 13 Tampilan hasil pendukung keputusan berdasarkan parameter.

\section{KESIMPULAN DAN SARAN}

Pengukuran konsumsi dapat dilakukan dengan implementasi perangkat IoT berupa sensor PZEM- 004T yang berfungsi untuk mendapatkan penggunaan tegangan arus dan daya pada listrik berjenis AC (Alternate Current). Berdasarkan data pengujian konsumsi energi oleh sensor dari hari pertama sampai dengan hari ketujuh kerja, tidak diperoleh kenaikan penggunaan listrik yang signifikan sehingga penentuan pola konsumsi energi menggunakan sekuensial mining. Sensor PZEM tidak dapat mengirimkan data melalui internet jika menggunakan mikrokontroller yang memiliki modul wifi seperti wemos, nodemcu dan sebagainya, dikarenakan kode pada sensor dapat membuat kode mengirim data melalu internet tidak bekerja, begitupun sebaliknya. Berdasarkan hasil penelitian, inputan mining sebagai bahan untuk system pendukung keputusan adalah tegangan, daya dan arus yang digunakan.

Sistem ini diharapkan dapat di kembangkan menggunakan MCB agar data yang diperoleh dapat lebih bervariatif. System dapat melakukan pemberian pertimbangan peralatan hemat daya agar dapat lebih menggunakan energi yang efektif dan efisien dan penambahan modul sebagai pengirim data ke internet dan pemrosesan terpusat secara online.

\section{Daftar Pustaka}

[1] M. Bachtiar, "Prosedur Perancangan Sistem Pembangkit Listrik Tenaga Surya Untuk Perumahan (solar home system)," vol. 4(3), 2006.

[2] A. Saleh, "Implementasi Metode Klasifikasi Naive Bayes Dalam Memprediksi Besarnya Penggunaan Listrik Rumah Tangga," Creative Information Technology Journal, vol. 2(3), pp. 207-217, 2015.

[3]

[4] A. Sari, W. Wahyudi and M. Facta, "Peramalan Kebutuhan Beban Jangka Pendek Menggunakan Jaringan Syaraf Tiruan Backpropagation," 2011.

[5] M. I. Mahali, "Smart Door Lock Based On Internet of Things Concept With Mobile Backend as a Service," Jurnal Electronics, Informatics, and Vocational Education (ELINVO), vol. 1, p. 3, 2016.

[6] W. Wedashwara, S. Mabu and C. Ahmadi, "Parallel evolutionary association rule mining for efficient summarization of wireless sensor network data pattern. In Cyber and IT Service Management (CITSM)," International Conference, pp. 1-6, 2017.

[7] W. Wedashwara, S. Mabu, M. Obayashi and T. Kuremoto, "Evolutionary Rule Based Clustering for Making Fuzzy Object Oriented Database Models In Advanced Applied Informatics (IIAI- AAI)," International Congress, pp. 517-522, 2015.

[8] Despa, K. Ady, K. M, Mardiana and F. N. Gigih, "Smart Monitoring of Electrical 
Quantities Based on Single Board Computer BCM2835," 2015.

[9] Q. Liu, D. Dikpride and M. Yas UNOri, "Application of Phasor and Node Voltage Measurements to Monitoring Power Flow Stability," International Jurnal On Electrical ENgineering and Informatics, vol. 4, 2012.

[10] N. Gigih, K. M, P. Hanang, Mardiana and D. S. Hery, "Electricity, Temperature, and Network Utilization Monitoring at Lampung University Data Centre Using Low Cost Low Power Single Board Mini Computer," 2014.

[11] N. Habibi, S. Setiawidayat and M. \& Mukhsim, "Alat Monitoring Pemakaian Energi Listrik Berbasis Android Menggunakan Modul PZEM- 004T," Prosiding Seminar Nasional Teknologi Elektro Terapan 2017, vol. 01, no. 01, p. 6, October 2017.

[12] E. D. Meutia, "Internet of Things Keamanan dan Privasi," Seminar Nasional dan Expo Teknik Elektro, 2015.

[13] N. N. Chamim, "Penggunaan Microcontroller Sebagai Pendeteksi Posisi Dengan Menggunakan Sinyal GSM," Jurnal Informatika, vol. 4, no. 1 ,

[14] 2010.

[15] M. P. T. Sulistyanto, D. A. Nugraha and N. Sari, "Implementasi IoT (Internet of Things) Dalam Pembelajaran di Universitas
Kanjuruhan Malang," SMARTICS Journal, vol. 1, no. 1, 2015.

[16] C. A. Aryanto, "Pengembangan Web Layanan Konsumen dan Penjaminan Mutu PT Pura Barutama Unit Boxindo dengan Framework Laravel dan Materialize," 2017.

[17] N. Yustina, "Sistem Pendukung Keputusan Pemilihan Lensa Kontak Bagi Penderita Kelainan Refraksi Mata Menggunakan Metode Simple Additive Weighting," vol. 1, 2013.

[18] E. Turban, E. J. Aronson and T. P. Liang, "Decision Support Sistems and Inteligent Sistem, Jilid 1," 2005.

[19] M. R. Fachri, I. D. Sara and Y. \& Away, "Pemantauan Parameter Panel Surya Berbasis Arduino secara Real Time," 2015.

[20] D. Permata, "Analisis Rangkaian Elektrik," 2011.

[21] S. S, "Analisi Rangkaian Listrik," 2002.

[22] Bagye, W., Azizah, T., \& Zulkarnaen, M. F. (2018). ALAT PENGAMAN KANDANG BERBASIS MIKROKONTROLER ARDUINO UNO. Jurnal Informatika dan Rekayasa Elektronik, 1(2), 62-67.

[23] Bagye, W. (2018). Implementasi Jalur Komunikasi Global System Mobile (GSM) Untuk Kontrol Robot Jarak Jauh Berbasis Mikrikontroller Atmel89S52. Jurnal Informatika dan Rekayasa Elektronik, 1(1), 1-6. 